\title{
The In-Hospital Suicide: A Psychological Autopsy of a System Involving Borderline Dynamics
}

\author{
Kathleen A. Hughes, MD \\ Medical University of South Carolina, Charleston, South Carolina \\ Al Santos, MD \\ Medical University of South Carolina, Charleston, South Carolina
}

Follow this and additional works at: https://jdc.jefferson.edu/jeffjpsychiatry

Part of the Psychiatry Commons

Let us know how access to this document benefits you

\section{Recommended Citation}

Hughes, MD, Kathleen A. and Santos, MD, Al (1989) "The In-Hospital Suicide: A Psychological Autopsy of a System Involving Borderline Dynamics," Jefferson Journal of Psychiatry. Vol. 7 : Iss. 2 , Article 7.

DOI: https://doi.org/10.29046/JJP.007.2.005

Available at: https://jdc.jefferson.edu/jeffjpsychiatry/vol7/iss2/7

This Article is brought to you for free and open access by the Jefferson Digital Commons. The Jefferson Digital Commons is a service of Thomas Jefferson University's Center for Teaching and Learning (CTL). The Commons is a showcase for Jefferson books and journals, peer-reviewed scholarly publications, unique historical collections from the University archives, and teaching tools. The Jefferson Digital Commons allows researchers and interested readers anywhere in the world to learn about and keep up to date with Jefferson scholarship. This article has been accepted for inclusion in Jefferson Journal of Psychiatry by an authorized administrator of the Jefferson Digital Commons. For more information, please contact: JeffersonDigitalCommons@jefferson.edu. 


\title{
The In-Hospital Suicide: A Psychological Autopsy of a System Involving Borderline Dynamics
}

\author{
Kathleen A. Hughes, M.D. \\ Al Santos, M.D.
}

\section{INTRODUCTION}

This manuscript reviews principles of hospital management in the care of severe borderline patients with concomitant affective syndromes. The case presented highlights a process of experiential learning in a novice clinician (a beginning psychiatric resident) and illustrates several critical areas of concern with these patients. The following four facets of clinical management are discussed: 1) Failed attempts to understand borderline dynamics and subsequent countertransference reactions; 2) Staff resistance to consistent, honest and open acknowledgement of suicide potential; 3) Special risks when borderline dynamics are combined with affective syndromes; and 4) Possible suicide preventive measures and their relative effectiveness.

THE CASE

Present Illness

D.B. a 30 y.o. single, white, computer-repair woman was hospitalized after stating that she was "going to blow [her] brains out if [she didn't] get help." She was admitted to our inpatient service with a diagnosis of "bipolar affective disorder, polysubstance abuse, and borderline traits." One purpose of the admission was to facilitate the change from her outpatient therapist to one who would be able to "manage her hospitalizations which [the therapist felt] would be more frequent in the future."

D.B. had been under the care of a clinical psychologist and a general practitioner for $1 \frac{1}{2}$ years having been treated for depression and anxiety with various antidepressants, Xanax, and psychotherapy. The 6 weeks prior to admission were chaotic including loss of her female lover, physical injuries secondary to intoxication requiring hospitalization, legal entanglements secondary to assault of a friend and vandalism of her car, and work difficulties secondary to multiple absences. 


\section{Past History}

D.B. experienced episodes of increased energy, decreased sleep, and increased spending, lasting approximately a week at a time. She would initiate multiple projects during these times, leaving some unfinished when she "crashed." She denied any trouble with the law. The patient complained of cyclical depressions since age 6 . She had been sexually abused by both her father and her brother since childhood. She graduated from high school and married shortly thereafter. The marriage ended two years later. She had been pregnant twice, but both pregnancies were terminated by therapeutic abortion.

\section{Family History}

Two brothers had a positive family history for depression. A younger brother fatally shot himself eight months prior to her last hospitalization, while another attempted suicide at least once. She denied knowledge of any frank manic episodes in her family, but did mention periods of inappropriate joking and irritability in one brother. Her mother had multiple psychiatric hospitalizations, with a history suggestive of possible manic episodes in that she was said to leave home for days-weeks at a time without explanation.

At the time of hospitalization she had limited contact with her family, most of whom lived out of state. Her parents had been divorced for several years, and her mother had married and divorced twice. The patient's father was in a hospital receiving chemotherapy for leukemia at the time of her death.

\section{Physical and Mental Status}

D.B. appeared well-developed and well-nourished. She manifested moderate psychomotor retardation and poor eye contact. Her general emotional state was depressed with tearful episodes. Affectual responses were blunted. Her speech was slow with moderate response latency. Thought progression was logical and tight. Thought content was without delusions or obsessions, but did include a sense of hopelessness. There were no perceptual abnormalities. She was attentive and cooperative, oriented to all spheres, and recent and remote memory were intact. She provided abstract interpretation of proverbs. She denied homicidal and suicidal intent or ideation.

The physical examination was significant only for a sacral decubitus ulcer. Ancillary studies were remarkable only for elevated liver function tests.

\section{Hospital Course}

Hospital course will be presented with parallel commentary. The admitting diagnosis was of a bipolar disorder with possible borderline traits. Treatment with lithium was reinstated, with Xanax PRN for anxiety. As the clinical picture 
unfolded, the borderline features became more apparent. She proceeded to leave AMA less than 24 hours after admission, saying she had to care for her pets. She did return later that evening and was readmitted. The next day the team attempted to clarify goals of hospitalization. We stated that we would provide as safe an environment as we could, but acknowledged that if she chose to kill herself, we would, in all likelihood be unable to stop her.

During the first week there were arguments with staff over medication, dressing changes, and privileges. She experienced episodes of extreme anxiety with visible tremors and an increased startle response for which she requested Xanax. These were somewhat attenuated by talking and reassurance. Guided imagery was also used to relieve some of the anxiety. In addition, she was instructed to keep a journal of her thoughts and feelings during anxious episodes. She maintained her journal for approximately $11 / 2$ weeks. The content of the journal focused on conflict with staff, feeling "closed in," and not getting her needs met. Another staff member attempted to teach her relaxation techniques. The lithium level was in the therapeutic range. Debridement of the ulcer had not gone as well as expected, and it appeared that further surgery would be necessary with final closure requiring skin grafting.

The patient had two episodes of leaving the unit without permission, one time reporting that she had taken Xanax and drunk beer. Meetings with her family and her girlfriend were scheduled, however, only the girlfriend attended. We had tried on several occasions to contact the family, but the patient successfully blocked efforts to include her family in her treatment. During the meeting she became increasingly angry and left the room, but she returned shortly thereafter and was able to complete the meeting. Later that day, the patient was noted to be extremely lethargic and admitted taking several Xanax. Vital signs were stable. She was given ipecac, charcoal, and placed in seclusion while her room was searched.

The following seven days continued to be chaotic. Behavioral outbursts included throwing soda cans around room, threatening an elderly male patient, and spitting on her therapist. Discussions with the patient centered around our rationale for medication, her rage against her family and her need to project these emotions on to others. The splitting and projective identification used by D.B. as noted by changes in body language, facial expression, demeanor, and affect within the same few minutes were capable of inducing an uncomfortable sense of "identity diffusion" in the resident. At her last encounter with the resident D.B. requested to work on her anger with her brother who had abused her. The session focusing on her brother did not occur because of the patient's elopement.

The resident therapist experienced mixed emotions including relief to be "off the hook" for a session which she feared might escalate out of control. The decision was made by the treatment team that upon D.B.'s return, involuntary commitment to a high security unit would be indicated. Interestingly, the therapist argued the patient was not acutely suicidal, that she had been in this 
state for some time, and that requests for involuntary commitment were an overreaction. The resident finally yielded on the grounds that the team had agreed to do this if the patient left the ward without proper authorization. Later, as the resident completed the commitment papers, she remembered her fear from the day before and recognized that things were, indeed, out of control. The mixed feelings she was experiencing, she felt, were interfering with her judgment.

D.B. returned to the unit intoxicated at 8:30 p.m. Her possessions were searched, but she was not. Over the phone the resident informed D.B. of the plan for transferring her involuntarily to another hospital (in another city 100 miles away) and reminded her of the agreement with the team. She denied remembering the agreement and pleaded with the resident not to send her away. The resident remained firm, although highly ambivalent. She hung up on the resident. She walked to the bathroom followed by staff persons. Conversation was maintained. The patient reported that she was "All right;" the staff stated that they would have to open the door. The key was in the door as the gun went off.

The following information was obtained post-mortem: The patient apparently bought a gun after leaving the hospital and returned home. While at home she called her previous therapist and told her that she wanted to return to the hospital and asked that she contact the resident. According to the previous therapist, there was a loud noise in the background. When asked about the noise, D.B. told the therapist not to worry. Apparently, the patient had shot at a picture on the wall at home prior to returning to the hospital. She also called her girl friend and told her she didn't need to hide from her anymore.

Reactions to the suicide were remarkably similar in the therapist, staff and other patients. All felt a sense of personal responsibility for D.B.'s actions and performed a private catechism of possible preventative measures. Self-recriminations alternated with anger about the suicide and sorrow that such unbearable cruelty was so commonplace. Several meetings were held with patients and staff to process these feelings. Support of the resident was expressed both formally and informally immediately and in the ensuing months by faculty, staff, and peers.

\section{DISCUSSION}

Among many things, this case illustrates four important facets in the clinical management of suicidal patients with borderline dynamics and affective syndromes: 1) Failed attempts by staff at subjective empathy and subsequent countertransference reactions; 2) Staff resistance to consistent, honest and open acknowledgement of suicide potential; 3) Special risks when borderline dynamics are combined with affective syndromes; and 4) Possible suicide preventive measures and their relative effectiveness.

1) Failed Attempts To "Understand" Borderline Dynamics and Subsequent Counter- 
transference Reactions: A therapeutic system is vulnerable to disorganization upon the entry of a severely disturbed patient with a borderline personality disorder. This, in part, related to a tendency in mental health care providers to empathize with patients through identification. In individuals with primitive character pathology and identity disturbances, these efforts are often futile and counterproductive. An inability to engage the patient through empathy can often lead to disappointment and subsequent avoidance of the patient (1). Our patient's psychic disorganization and frenzy was reflected in the history of a very high level of psychic agitation/perturbation and chronic, erratic, impulsive, and dangerous behavior. The patient's psychic disorganization was mirrored in the poorly coordinated involvement of a large network of caregivers.

Patients with a borderline personality disorder who react intensely to their social world run the risk of making their caretakers feel frantic and rushed. Clinicians' reactions are individually determined by their own psychology and by the particular projection of the patient. Team members therefore are often at odds with each other (2). Our patient's frantic and futile efforts at anxiety relief were mirrored by the team's erratic treatment approaches. Examples of this include the multiple use of anxiolytic techniques such as daily diaries, imagery, various medications, dyadic interactions, and relaxation techniques.

The unique emotional reactions of severe borderline patients often do not respond favorably to traditional supportive measures. These patients experience extreme levels of anxiety which are often related to a sense of aloneness. When most people are lonely, they can comfort themselves because they know the feeling is transient. In people with borderline personalities the subjective experience is like being hopelessly cut off from all other humans (3). This death-like experience is usually accompanied by panic. This panic is often aborted by wrist slashing, intoxication, or promiscuity. Despite their dysfunctional consequences, these behaviors establish some personal control over the environment. This patient expressed fear of dying alone; and, perhaps, the hospital represented a place where she would be sure to be found.

Avoidance of this anxiety can be achieved through attachment to other people, animals, or even inanimate objects or physical characteristics (2). These external objects can act as anchors to social reality or "sustaining resources" (3). When these are lost, there is a return to psychotic chaos with the possibility of dangerous acting out as was evidenced in this case by the assault on the patient's closest friend. A patient with such an extremely intense and unstable affectual state without gross psychotic symptoms presents a special challenge to clinicians.

Warnings against trying to identify with primitive states or to empathize with borderlines abound. Theirs is a human experience outside the realm of usual possibilities for "identification" through sympathy, empathy or kindness. Yet, we try anyway. The resident's attempt to empathize with this patient's outrage for the sexual abuse and the unresolved feelings about her brother's suicide clearly did not provide the resident with an accurate "understanding" of her suffering. 
Borderline dysphoria has been described as an agonizing, agitated, rageful state where only negative aspects of the self are appreciated and a propensity toward violence exists (4). This state was, perhaps, most graphically depicted during the episodes when the patient "vibrated with anger" and described "holding on with [her] fingernails" which attenuated with reassurance and anxiolytics. Maltsberger (1986) suggests that the greater the self-judging conscience or superego, the greater the likelihood of suicide in order to control the agitation, fury, and murderous rage (3). Our patient struggled with this conflict until her death as evidenced by assaults against property, others, and, ultimately, herself.

Borderline patients are thus at great risk for negative countertransference reactions (1). We are usually unable to gain empathy in regard to their unique states of psychic disorganization, anxiety, loneliness, and dysphoria. In their efforts to relieve anxiety, be something, and restructure their environments, they often deliver a narcissistic blow to their caregivers. The therapist's negative feelings towards the patient are often resolved through defensive distancing and avoidance. Sometimes, treatment is terminated through unconscious sabotage (i.e., "If you try suicide again, I won't treat you"). One would wonder about this as an operative dynamic in this case in regard to the decision of transfer involuntarily to the high security psychiatric hospital. It is important to appreciate that clinicians and families unconsciously and consciously wish to be rid of the problem patient and may provide ways for that to happen. The patient eloped when she was allowed to make a call off the ward without an escort. Kernberg (1984) suggests the best way to manage such "death wishes" is to take them seriously and consider the contamination they bring to patient's environment (5). It is much less dangerous to acknowledge one's negative countertransference than to react with active distancing and avoidance $(1,5)$.

2) Staff Resistance to Consistent, Honest and Open Acknowledgement of Suicide Potential: This case also highlights the indication for continuous acknowledgement of suicide potential and honest communication with each other and our patients about this risk. A wareness and acceptance of our limitations about both prediction and prevention of violence are important. It is, of course, difficult to be open with our patients if we are not first honest with ourselves. Consistent, open acknowledgement of the self-destructive aspects of borderline patient's behavior is necessary. Our patient's suicidal risk was not consistently addressed. In the week prior to her death, suicide is not once mentioned in the progress notes. Perhaps, this omission is illustrative of the staff's wish to engage in "superficial, friendly" discussions while denying the self-destructive aspects of her behavior (5). Also, the patient was taking antidepressant medication with some improvement in affective symptoms. While in early recovery from a depression, she was again at increased risk for suicide, this was known but, perhaps, not appreciated at the time by the staff. The resident's difficulty in understanding the acute suicidality of the patient on the day of her death negated an appreciation of the aggressive forces in operation. 
Further, the therapist needs to remain alert to the manipulative aspects of the patient's self-destructive behavior. In order to assess and circumvent these behaviors, work with the support system is crucial. Our patient sabotaged family involvement. Further recommendations by Kernberg (1984) to avoid reinforcement of the patient's self-destructive behaviors include: convey to patient that one would feel sad with the patient's death, but would not be responsible and life would go on; alert the family that the patient possibly has a psychiatric malignancy and might die at any time; express a willingness to treat without guarantees; and refuse to treat in situations which require "heroic efforts" (5).

Our frank ineptness at predicting violence must be clearly appreciated by all clinicians, patients, and families involved. This acknowledgement may facilitate greater honesty in communications. Cocozza and Steadman (1976) attempted to assess dangerousness in felons who were found incompetent to stand trial. Of 267 males examined, 154 were deemed dangerous and 113 were thought not to be dangerous. While confined, $57 \%$ of those considered dangerous were assaultive, while $39 \%$ of those considered not dangerous were assaultive. After being released, $16 \%$ of those considered dangerous were assaultive and $23 \%$ of those considered not dangerous were assaultive. There was no difference in frequency of assaultive behavior between the two groups beyond that obtainable by chance (6).

There is probably a public perception that mental health professionals are reasonable predictors of violence. Perhaps, in the future we will be able to utilize biological markers to assess likelihood of lethal suicide attempts. Asberg et al (1976) found patients with lowered CSF 5-HIAA to make more suicide attempts by more violent methods than those without low CSF 5-HIAA (8). Banki et al (1981) found a negative correlation between suicide ratings and CSF 5-HIAA (9). For now, however, our patients have nothing to gain by overconfidence on our part about our predictive skills.

3) Special Risks When Borderline Dynamics Are Combined With Affective Syndromes: In this case we were confronted with the complex diagnostic task of teasing out elements of a personality disorder from those of an affective syndrome, a task which is difficult and theoretically controversial. Akiskal et al. (1979) studied 100 consecutive patients with neurotic depression operationally defined as a nonpsychotic depression occurring in the context of disturbing life circumstances with few or no vegetative signs, no marked disturbance in psychomotor sphere and preponderance of subjective symptoms of depression in an individual with varying degrees of neurotic character pathology (10). Two-thirds of the cases met Washington University criteria for probable depression and one-third for definite depression. These patients were followed over 3-4 years and fell into several categories: $40 \%$ had primary affective illness; $48 \%$ with nonaffective disorders with concomitant depressive symptomatology; and $12 \%$ remained classified as undiagnosed probable depression. They found external variables which helped predict which of the neurotic depressions would ultimately fall into the primary affective group. Pharmacologic hypomania in response to 
tricyclics, a positive family history of bipolar illness, positive family history of affective disorder in successive generations, "loaded" pedigrees (3 or more affected kin), and a positive family history of suicide were all predictive of a primary affective disorder. Shortened REM latency has also been correlated with primary affective illness (11). A further complication in our case was the possibility of rapid cycling, possibly induced by the use of a tricyclic antidepressant (12).

The separation of Axis I and Axis II disorders in the DSM-III-R has the potential for polarizing clinical decision-makers into adopting what is likely to represent a false mind-body dichotomy. A prospective approach with input from behavioral genetics, psychometry, pharmacologic dissections, and other biological markers may prove productive (13). Clearly, the greatest danger is the tendency to see the patient as either affective or characterological while ignoring the possibility of interplay or that these may be different facets of the same phenomena.

4) Possible Preventive Measures and Their Relative Effectiveness: To what degree might this or other suicides be avoided through successful preventive measures? In cases of borderline disorders with acute affective illnesses, it may be safest to assume that immediate hospitalization is indicated as suicide risk is high. Suicide attempts are most frequent during early recovery from affective illnesses, and in these cases, suicidal intentions are blurred by reappearance of underlying character disorder. Premature discharge of depressed patients because of dramatic improvement and denial of suicidal ideation is a factor in encouraging suicide after discharge.

In borderline patients without major affective illness or any other psychotic syndrome, one may entertain the notion of outpatient treatment. Kernberg (1984) warns that if a patient is considered dishonest, especially with regard to previous suicide attempts, alcoholism, or drug abuse, it is best not to attempt outpatient treatment. Dishonesty may be manifest, for example, in patients who appear indifferent, bland, or derogatory toward the clinician while reporting suicidal ideation (5). If containment is indicated, we must utilize all social and legal resources to secure safety.

Other potential in-hospital preventive measures include:

a) Increased use of 1:1 observation. Arguments in favor of and opposed to this strategy exist. Some authors suggest that special precautions may be so exaggerated as to bring about an attempt through suggestion or that extremely severe restriction may lead to suicide because of increased discomfort and/or adoption of a "suicidal identity" (14). These authors claim some clinical evidence for the assumption that if psychiatric personnel do not treat a patient as a suicide risk, the probability will decrease. However, if suicide precautions are to be successful, they must be carefully adhered to by staff and include constant observations (15).

b) Aggressive treatment of affective symptoms. This should include the use of antidepressants and/or neuroleptics and consideration of ECT. Modestin and 
Boker (1985) suggest that the most appropriate initial treatment for a highly suicidal patient with psychotic depressive symptomatology and a high level of tension would be immediate powerful sedation to the extent of inducing psychopharmacological sleep with sedative neuroleptics, with addition of benzodiazepine, or barbiturates if necessary" (14).

c) Changes in search procedures. Staff members have resisted body searches of patients for various reasons including violation of civil rights, interference with treatment, or the possible provocation of violent behavior. McCullough et al. (1986) reviewed the institution of a weapon-screening program in a psychiatric emergency room (16). They reviewed staff attitudes to the procedure before instituting the screening and patient and staff attitudes after screening had been in place for 4 months. Prior to screening, $41 \%$ of staff felt the procedure would negatively affect patient care. After the procedure was initiated, $88 \%$ of staff and $84 \%$ of patients felt weapon screening was a good idea. Only $11 \%$ of staff and $15 \%$ of patients felt it violated patients' civil rights. $93 \%$ of staff and $76 \%$ of patients stated that they felt safer with the use of weapon screening. Incidentally, $8 \%$ of the patients screened were carrying weapons, often without staff suspicion. These results do not support the idea that patients will be adversely affected by weapon searches.

d) Transfer to more restrictive environment. Our patient was hospitalized in an 18-bed, double-room, open ward. Consideration of transfer to a locked ward was initially entertained by the treatment team, but was dismissed because the patient was undergoing serial debridements. Also, the team felt that the patient had made a tentative alliance with the resident and wished to avoid the development of abandonment rage. The decision to transfer to the high security hospital in another city, however, was possibly motivated by countertransference and possibly precipitated the suicide.

e) Monitoring of important systems changes. Conroy and Smith (1983) found that in 19 consecutive cases of inpatient suicide occurring over many years, 18 out of 19 cases (95 percent) were found to have a significant object loss affecting the suicide (17). These included the loss of powerful institutional attachment, estrangement from the family (real or imagined), divorce or separation, death or illness of a significant other, or a family that insisted on continued treatment and/or growth. Significant communication from or about the lost object which seemed to have an impact on the suicidal behavior often occurred within days of the final event. In about one-half the cases, the family had visited within two weeks of death. In $42 \%$ of cases, the significant communication occurred within 3 days of suicide. Maltsberger (1985) emphasizes the value of self-object reliance (4). Given that borderline patients have a severely dysfunctional self-concept and identity formation, they need to rely on their support system as "external sustaining resources." Sometimes the therapists are "professional external sustaining resources" (3). Oldham and Russakoff (1984) reviewed 19 suicides of inpatients, day hospital patients, and outpatients over a 3-year period (18). Eight 
of 19 patients had been recently discharged and 7 of the remaining 11 committed suicide within 2 weeks of a scheduled therapist change.

Treatment teams need to be especially alert to communication from and about significant others in individuals already suspected to be suicide prone. The difficulty of ascertaining a loss and the communication of its significance among treatment team members should not be underestimated.

\section{SUMMARY}

Patients with borderline personalities present unique challenges to psychiatric providers. Their interpersonal interactions often result in marked countertransference responses which are potentially dangerous to the patients. Providers are inclined to avoid such patients and in so doing may sabotage treatment efforts. It is of critical importance that such countertransference responses be identified and openly acknowledged. The potential of dangerous behavior must be addressed seriously and realistically with all parties involved. When borderline patients suffer from a concomitant major affective illness, it is imperative that Axis I and II symptoms be evaluated and managed separately. The risk of dangerous behavior will be greater in this group and, hence, preventive measures must be heightened.

\section{REFERENCES}

1. Maltsberger JT, Buie DH: Countertransference hate in the treatment of suicidal patients. Arch Gen Psychiatry 30:625-633, 1974

2. Selzer MA, Koenigsberg HW, Kernberg OF: The initial contract in the treatment of Borderline patients. Am J Psychiatry 144:927-930, 1987

3. Maltsberger JJ: Suicide Risk: The Formulation of Clinical Judgment. New York, 1986

4. Maltsberger JJ: Management of suicidal risk in borderline patients (workshop). Hospital and Community Psychiatry, Annual Meeting, Montreal, Canada, 1985

5. Kernberg O: Severe Personality Disorders: Psychotherapeutic Strategies. Yale University, 1984.

6. Cocozza JJ, Steadman HJ: The failure of psychiatric predictions of dangerousness: Clear and convincing evidence. Rutgers Law Review 29(5):1084-1101, 1976

7. Van Praag H: Depression, suicide, and serotonin metabolism in the brain. In Neurobiology of Mood Disorders. Edited by Post RM, Ballenger JC. Williams and Wilkins, 1984

8. Asberg M, Traskman L, Thoren P: 5-HIAA in the cerebrospinal fluid. A biochemical suicide predictor? Arch Gen Psychiatry 33:1 193-1197, 1976

9. Banki C, Molnar G, Vojnik M: Cerebrospinal fluid amine metabolites, tryptophan and clinical parameters in depression. II. Psychopathological symptoms. J Affective Disord 3:91-99, 1981

10. Akiskal HS, Rosenthal RH, Rosenthal, TL, et al: Differentiation of primary affective illness from situational, symptomatic, and secondary depression. Arch Gen Psychiatry 36:635-643, 1979 
11. Akiskal HS, Rosenthal TL, Haykm RF, et al: Characterological depressions. Arch Gen Psychiatry 37:777-783, 1980

12. Kukopulos A, Reginaldi D, Laddomada P, et al: Course of the manic-depressive cycle and changes caused by treatments. Pharmacopsychiatria 13:156-157, 1980

13. Akiskal HS, Hirschfeld RMA, Yervanian BI: The relationship of personality to affective disorders. Arch Gen Psychiatry 40:801-810, 1983

14. Modestin J, Boker W: Homicide in a psychiatric institution. British Journal of Psychiatry, 146:321-324, 1985

15. Gale S, Mesnikoff A, Fine J, Talbott J: A study of suicide in state mental hospitals in New York City. Psychiatric Quarterly 52:201-213, 1980

16. McCullugh I, McNeil E, Binder R, et al.: Effects of a weapons screening procedure in a psychiatric emergency room. Hospital and Community Psychiatry 37:837-838, 1986

17. Conroy R, Smith K: Family loss and hospital suicide. Suicide and life-threatening behavior, 13:179-194, 1983

18. Oldham J \& Russakoff L: Suicide at a training center. Journal of Psychiatric Education Vol 97:104, 1984 